\title{
CSF2 Antibody
}

National Cancer Institute

\section{Source}

National Cancer Institute. CSF2 Antibody. NCI Thesaurus. Code C118899.

Any antibody that recognizes the granulocyte-macrophage colony-stimulating factor protein. 